\title{
A Preliminary Design of BatiKids: A Game-Based Learning to Support Children Learning the Process of Producing Traditional Batik in Museum Context
}

\author{
Hestiasari Rante, Heidi Schelhowe, and Michael Lund, Member, IACSIT
}

\begin{abstract}
This paper presents the preliminary design of BatiKids, a game-based learning that designed to support young children to learn producing batik within the museum context. The game is intended to install in the Museum Batik Pekalongan in Indonesia, as one of the research fields of the study. The game will give children the opportunity to learn each step of the traditional technique, but also eliminate the complex problem during the long process and tight sequences of producing a piece of batik. In addition, this game will be a playful tool for young children and offer them some batik ornaments and great variations of color and shade without being a master in the complicated blending of successive layers of color.

The method used in designing the game is participatory design including interviews, paper prototyping and usability tests. Results from this study are used to improve the game and to suggest directions for future works in this study.
\end{abstract}

Index Terms - Batik, children, digital media, game-based learning, museum, software.

\section{INTRODUCTION}

Playing computer games is an extremely popular leisure activity for children now in digital era. Children are willing to devote considerable amounts of their time to play games. Based on the popularity and strong motivational effect of computer games among children, educators have started to consider how games can be used in educational settings [1].

In a study conducted by the Teachers Evaluating Educational Multimedia (TEEM) organization [2], it was reported that the children rarely gained knowledge from the game content which was directly applicable to other areas of the curriculum. However, they did find some games useful as a stimulus to other creative activities, such as writing stories and drawing about popular game characters or scenarios. The teachers also valued the skills, which the children developed directly from playing the game, or indirectly from working in

Manuscript received November 24, 2014; revised January 27, 2015. This study was supported by the Directorate General of Higher Education (DIKTI), Republic of Indonesia and by the Central Research Development Fund of the University of Bremen, Germany.

Hestiasari Rante is with the Digital Media in Education (DiMeB) Research Group, the Department of Computer Science, University of Bremen, Germany. He is also the Department of Creative Multimedia, Electronics Engineering Polytechnic Institute of Surabaya, Indonesia (e-mail: rante@informatik.uni-bremen.de).

Heidi Schelhowe and Michael Lund are with the Digital Media in Education (DiMeB) Research Group, the Department of Computer Science, University of Bremen, Germany (e-mail: schelhow@tzi.de, mlund@informatik.uni-bremen.de). a group on a game-playing task.

Aside from schools, educators also think that museums are also a promising place for children to learn, especially when it comes to art, cultural heritage, and history topics. Museums nowadays considered not only as for exhibiting art objects, which are most rare, most beautiful and most antique, but they have been involved in educational concerns. Millions of children a year go to museums whether to be entertained on a rainy day, or to learn about something they cannot have in school or at home. Somehow, children know that they can have fun in museum since museum has a special meaning for children.

Meanwhile the interactive technology-enhanced museum experiences seem to be a recent development, they in fact have had a relatively long, rich history. Since the 1960s at the establishment of such science and technology museums as the Exploratorium in San Francisco, CA, children have been able to explore complex concepts with physically interactive experiences [3]. Today there are hundreds of these sorts of museums all over the world. Children can explore anything they are curious on at the museum. Children can interact with information that is reactive to their touch, movement, or voice. They can play the role of an explorer, scientist, or artist as they manipulate images, sound, physical objects and more [4]. This sophisticated use of physical interactive spaces is something that has been studied in the Human-Computer Interaction field for many years in the form of tangible user interfaces [5]-[7], ubiquitous computing [8] and augmented environments [9].

The rapid growth of the technology also gives a significant impact to cultural heritage learning. Children need to learn the culture in a way according to their affection. Technology has a powerful influence in enhancing children's learning on culture. Batik as one of Indonesian cultural heritage is brought into this study and is introduced to children in a different platform. Batik is an art form with strong tradition aspects. Some batik museums in Indonesia have huge collections of beautiful and precious batik, but it is necessary that museum also have to deliver the knowledge of producing batik, which is including the craftsmanship and the creative design. Batik museums could use the traditional method of producing batik, but the innovation in digital technology would be another option, especially for children, to teach the process of making batik [10].

This study will present the preliminary design of BatiKids; a game-based learning designed to support children learning the complex process of producing traditional batik in museum context. 


\section{Museum Batik PeKalongan}

In Indonesia the technique of drawing batik pattern on fabric is an ancient method. Batik craftsmen use traditional tools called canting and cap to create intricate designs. The main process generally consists of eight steps: 1) Nyungging Sketching and drawing pattern on a paper. 2) Njaplak Moving the drawn pattern on paper to the fabric. 3) Nglowong - Waxing pattern on fabric with canting. 4) Ngiseni - Putting isen (fill) to the main pattern. 5) Nyolet - Coloring some parts of the pattern using paintbrush. 6) Mopok - Covering parts that have been colored with wax using paintbrush. 7) Ngelir Coloring the whole fabric by putting fabric into colored water. 8) Nglorod - Removing wax by pouring fabric into boiling water.

Fig. 1 is showing the real canting used in the process of making traditional batik.

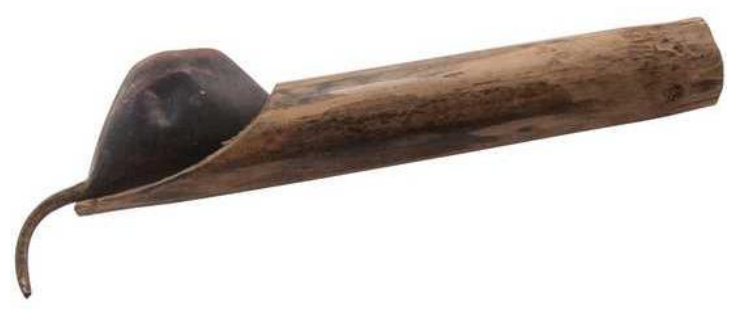

Fig. 1. Canting.

It is difficult to say how long exactly it needs to produce a piece of batik. Sometimes it takes three months, six months, or even a year; it depends on the patterns, colors, and length-width of the cloth [10]. The traditional process of producing a piece of batik is not easy and consumes a lot of time. The technique also requires precision and incredible patience. However, this culture heritage needs to be delivered to young people and children, hence they can continue to manage and maintain it. Therefore it is really challenging to find another technique to deliver the skill, which is more interesting for young children.

Museum Batik Pekalongan in Indonesia provides huge and precious batik collections. Being aware that museum also has a role to involve in education, this museum provides free workshop daily for visitors who want to learn producing traditional batik. Due to limited time, the workshop cannot show the whole process, but only some interesting steps of the process, e.g. drawing pattern then waxing the pattern on fabric using canting. This workshop is not enough to transfer the knowledge and to deliver the skills of making batik.

The museum also provides a comfortable audio-visual room where visitors can watch the video of the proses of making batik. Through this video visitor will get the visualization of making batik in traditional method from the beginning until end. But visualization method is also not enough. Visitors need to touch and to practice the process in a real environment. Just like any other skill, people need to practice.

With the specific demands on Museum Batik Pekalongan, I started to develop BatiKids. Not only limitation of resources in museum, but also the special patterns belong to the museum, the information displayed and duration of the game have to be taken into consideration. At the museum, the game will be installed on some PC and children will play it using mouse.

\section{BATIKIDS}

The approach that is used in developing the game is participatory design. From the start, we engaged museum staff, museum experts, and some children in the creative process as we collaborate, experiment and prototype. The resulting of the first prototype integrates the physical, digital and social interaction into a transformative experience.

It is essential to understand how the digital environment might affect children's cognitive development. In this study, there are two key issues in designing for children: 1) deciding how to translate physical environments to digital space; and 2) translating each step of the process of making batik into what children might consider a meaningful visualization.

Another point that has to be considered is that batik is not about drawing the patterns but about including the technique and the whole process of producing batik. This has to be integral part on the tool to be designed [10].

\section{A. Character}

Character is one of the essential parts of a game. It can identify the game-player's motivation and related to the playing time [11]. On the other hand, it is also important for branding a game [12]. Burgerman wrote some simple but very useful tips to design a character. Character design can be a tricky beast to tackle, because although many of the classic characters familiar to us through cartoons, movies and advertising look simple, that simplicity usually belies the many hours of work that have gone into their development [13].

\section{1) Who it is aimed at}

Children aged 4-11 years are the main user targets in this study. Children love characters. The game is about Indonesian culture. I spent some times to create characters with strong visual identities and personalities that brought Indonesian children style.

\section{2) Research other existing designs}

After having a rough idea or design, it can be helpful to do a research on other existing design. There is no shortage of research material to be found, with illustrated characters appearing everywhere: on TV commercials, cereal boxes, shop signs, stickers on fruit, animations on mobile phones, and more. While studying these character designs, it is important to think about what makes some successful and what in particular user or customer like about them [13].

\section{3) Make the character distinctive}

The character design needs to be strong and interesting in a visual sense to get children's attention. A strong visual identity is key; therefore I created two little children characters wearing grey t-shirt with pants and long skirt from tenun lurik, a special woven from Indonesia. Hairs and eyes are designed as specific as possible so the characters look like Indonesian children.

Many kids are not great at remembering a lot of names [14]. However, it is necessary to name the characters. I use a simple Indonesian name that can be easily pronounced by children and I introduce the name since the very beginning of the game. The names are Dewa for the little boy character, and Dewi for the little girl character. Fig. 2 is showing Dewa and Dewi characters for BatiKids. 


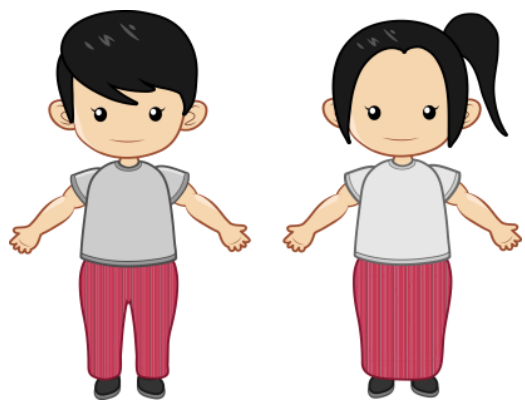

Fig. 2. BatiKids characters: Dewa and Dewi.

\section{B. Scenario and Prototype}

Children love choices, even if they are superficial. I develop a game that let children to have some opportunities to choose what they like and what they want to do first. Making a choice is sometimes not easy for children, but this game will be entertaining and they will make a choice for fun.

At the first page, children will choose which level of game they want to play. It is strongly suggested that children aged 4-8 years take Level 1 first. For children aged 9-11 years, they could go straight to Level 2 . The dissimilarity between Level 1 and Level 2 is presented in Table I.

Children may also choose if they want to have Dewa or Dewi as their virtual friend who will accompany them during the game.

TABLE I: TWO LEVELS OF BATIKIDS

\begin{tabular}{|c|c|}
\hline Level 1 & Level 2 \\
\hline $\begin{array}{l}\text { - Drawing the pattern by } \\
\text { following dots on the } \\
\text { ornament object } \\
\text { - Choosing the background color } \\
\text { for the batik } \\
\text { - Mixing colors } \\
\text { - Coloring patterns with mixed } \\
\text { colors } \\
\text { - Removing the color if they do } \\
\text { not like it and change it } \\
\text { with another (mixed) color } \\
\text { - Saving the work and getting the } \\
\text { batik pattern ready for the } \\
\text { next steps }\end{array}$ & $\begin{array}{l}\text { - Drawing the pattern by } \\
\text { following dots on the } \\
\text { ornament object } \\
\text { - Choosing the background color } \\
\text { for the batik } \\
\text { - Mixing colors } \\
\text { - Coloring patterns with mixed } \\
\text { colors } \\
\text { - Removing the color if they do } \\
\text { not like it and change it with } \\
\text { another (mixed) color } \\
\text { - Multiplying the pattern } \\
\text { - Modifying the pattern: resizing, } \\
\text { rotating, and flipping } \\
\text { - Saving the work and getting the } \\
\text { batik pattern ready for the } \\
\text { next steps }\end{array}$ \\
\hline
\end{tabular}

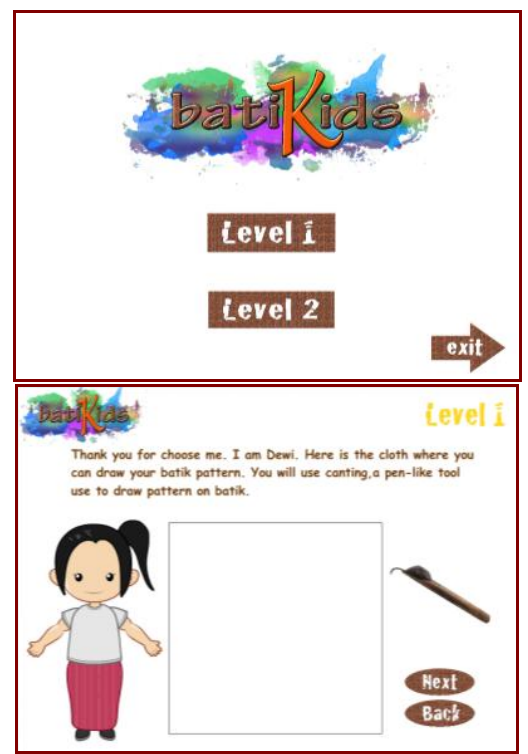

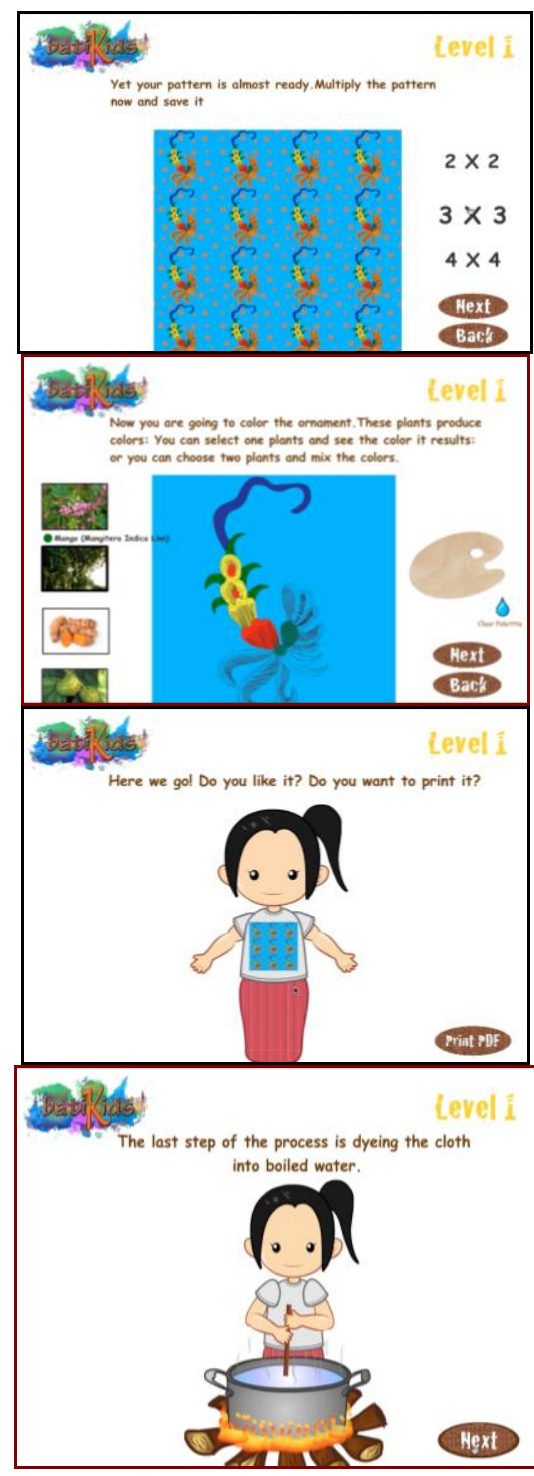

Fig. 3. BatiKids prototype.

Children love to play with colors. They can choose and mix the colors in this game. There are only four colors given on the game; if they mixed two or three of the colors, they will get a new color. The four colors are resulted from plants in reality. This part aims to show children plants they can see in everyday life; plants that can result nice colors and be used for fabrics.

Choosing an ornament of pattern is also part of this game. There are three ornaments provided and children may choose one they like to draw and to color. More detailed activity on the game is showing in Table I. In the end, children will see the pattern they have drawn and colored appear on t-shirt of Dewa or Dewi.

Fig. 3 is showing some screenshots of BatiKids prototype.

\section{RESULT}

BatiKids helps children to learn and do the process of producing batik in a more fascinating way and within a short time when using computers instead of doing it in traditional ways. The game even gives the opportunity to easily modify children's work if needed; whereas this is not possible to do in traditional way. The game is also very safe for children, as they do not need to intersect with hot wax, hot water and also 
fire that are used for the real process.

The power of digital media not only showing the traditional handcraft in better way but also giving the specific aesthetic concepts embedded in a cultural game-based learning.

We gathered the first result by doing paper prototype test and testing the first interactive prototype with small group of young children. The following aspects we gathered after testing and interviewing the children.

- Children enjoyed the game and some of them could not stop to play it.

- Children could understand the process shown on the game but still could not imagine how it is in the real process.

- Children with less confidence of doing a handcraft in reality became more confidence to try out the game.

- Given the chance to go back to previous pages is a good function for children, as they could rework on their pattern.

- Most of the children got problem when drawing the pattern with mouse. Driving mouse following dots on the object is definitely not easy.

\section{CONCLUSION AND FUTURE WORK}

We assume that through this game-based learning designed with participatory design method, a model of application installed in museum context will be a support to the museum to deliver the knowledge and skill of producing batik.

From the current stage of result, we conclude that an interactive game for children, especially for learning purpose needs narration to make it more understandable. Narration for BatiKids will be given as voice over that tells the history behind the patterns.

Other future works will be including adding backsound, adding video of the real process, embedding the game into a tablet or touch-screen tool and constructing a real canting to be used as a pen-tool for the tablet in order to strengthen the reference between virtual and real activities derived from the making batik in traditional way. Further work and discussion with museum and batik experts is also planned when the game has been reconfigured.

\section{ACKNOWLEDGMENT}

We thank the children who participated in the study. We would also like to thank the three internship students; Kanjana Jettammakun, Kanokporn Rattanacharoenporn and Napassawan Tangamporn from King Mongkut's University of Technology Thonburi, Thailand for their contribution in this study.

\section{REFERENCES}

[1] J. Robertson and J. Good, "Children's narrative development through computer game authoring," in Proc. the 2004 Conference on Interaction Design and Children: Building a Community (IDC2004), pp. 57-64, New York, USA: ACM, 2004.

[2] A. McFarlane, A. Sparrowhawk, and Y. Heald. (2002). Report on the educational use of computer games. Teachers Evaluating Educational Multimedia (TEEM) Report. [Online]. Available: http://www.kennisnet.nl/uploads/tx_kncontentelements/games_in_ed ucation_full1.pdf

[3] R. J. Semper, "Science museums as environments for learning," Physics Today, vol. 43, no. 11, pp. 50-56, 1990.

[4] A. Durin, "Museums, children, and technology," Newsletter, ACM SIGCHI Bulletin - A Supplement to Interactions, vol. 2001, p. 6 , November-December 2001.

[5] H. Ishii and B. Ullmer, "Tangible bits: Towards seamless interfaces between people, bits, and atoms," in Proc. CHI 97, ACM Press, pp. 234-241, 1997.

[6] G. Fitzmaurice, H. Ishii, and W. Buxton, "Bricks: Laying the foundations for graspable user interfaces," in Proc. CHI 95, ACM Press, pp. 442-449, 1995.

[7] B. L. Harrison, K. P. Fishkin, A. Gujar, C. Mochon, and R. Want, "Squeeze me, hold me, tilt me! An exploration of manipulative user interfaces," in Proc. CHI 98, ACM Press, pp. 17-24, 1998.

[8] M. Weisner, "The computer for the 21st Century," Scientific American, vol. 265 , no. 3, pp. 94-104, 1991.

[9] P. Wellner, W. Mackay, and R. Gold, "Computer augmented environments: Back to the real world," Communications of the ACM, vol. 36, no. 7, July 1993.

[10] H. Rante, M. Lund, and H. Schelhowe, "A digital batik tool Supporting children in understanding and constructing traditional batik patterns within a museum context," International Journal of Multidisciplinary Education and Research (IJMER), vol. 1, no. 2, 2014.

[11] E. A. van Reijmersdala, J. Janszb, O. Petersc, and G. van Noorta, "Why girls go pink: Game character identification and game-players' motivations," Computers in Human Behavior, vol. 29, issue 6, pp. 2640-2649, November 2013.

[12] Y. K. Choia, S. Yoonb, and H. P. Laceyc, "Online game characters' influence on brand trust: Self-disclosure, group membership, and product type," Journal of Business Research, vol. 66, issue 8, pp. 996-1003, August 2013.

[13] J. Burgerman. (2013). 20 Character Design Tips. [Online]. Available: http://www.creativebloq.com/character-design/tips-5132643

[14] P. Hoffstein. (2013). Games for Kids. [Online]. Available: http://phoffstein.wordpress.com/essays/designing-games-for-kids/

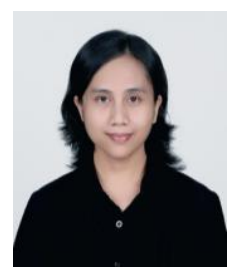

Hestiasari Rante is a PhD candidate at the Digital Media in Education (DiMeB) Research Group, the Department of Computer Science, University of Bremen, Germany. She works under the supervision of Prof. Dr. Heidi Schelhowe. She is also related to the Department of Creative Multimedia, Electronics Engineering Polytechnic Institute of Surabaya, Indonesia where she worked as a lecturer, but is currently on leave. Her research interest is child-computer interaction focused on digital media that supports education and culture. 